\title{
A study on different factors influencing on empowering employees: Evidence from food industry
}

\author{
Masod Pourkiani and Ali Naderifar
}

Department of Management, Islamic Azad University, Kerman Branch, Kerman, Iran

\section{H R O N I C L E}

Article history:

Received June 4, 2014

Accepted 2 November 2014

Available online

November 102014

Empowering

Food industry

Human resources development

\section{Introduction}

During the past few years, several researchers have interested in empowering employees and provided valuable results for firms across the world. Empowerment is a concept, philosophy, or set of organizational practices where a firm vests decision-making or approval authority to employees. Empowerment is a set of policies helping self-managing teams and individuals become in charge of careers and destinies. Empowering employee's breeds success by giving the framework to the workforce to unleash, to develop, and to utilize skills to realize organizational objectives (Sadati, 2012). Empowerment is a type of a journey to a destination (Kaye \& Jordan-Evans, 2002) and today's business environment needs administrators to visualize the direction the organization very clearly (Baird, 2006). Primarily, employee empowerment is granting power to the stakeholders executing the work (Petter et al., 2002). Many empowerment programs are based on innovation, bigger effectiveness, and better performance (Castello, 2002) but many people think more about it. It needs skill, dynamics, and communication techniques, which could be time consuming (Petter, et al., 2002).

*Corresponding author.

E-mail addresses: ali.naderifar@yahoo.com (A. Naderifar)

(c) 2014 Growing Science Ltd. All rights reserved.

doi: $10.5267 /$ j.ms 1.2014 .11 .005 
Empowerment programs, to be effective, require the full support of management throughout the process and empowerment necessities to be an ongoing concern (Baird, 2006). Empowerment is a philosophical idea or a set of organizational behavioral practices where a firm vests decision-making or approval authority to employees. Empowerment is policies helping self-managing teams and employees become in charge of careers and destinies. Empowering employee's breeds success by providing the framework to the workforce to utilize the important skills to reach organizational objectives. These kinds of programs place the responsibility for decisions further within the organization (Petter et al., 2000). Empowerment is making all stakeholders responsible for daily tasks and the everyday jobs at hand (Messmer, 2004). Empowerment does not defend giving up control, but rather changing the way control is implemented (Messmer, 2004). Empowering employees gives them bigger responsibility and it is an effective application of a firm's vision for the development and utilization of the human resource asset (Baird, 2006). Empowerment changes the organizational culture to reduce the conflict between the objectives of organizations and individuals (Petter, et al., 2000 cited in Baird, 2006). According to Darvish et al. (2013), training programs may increase employees' self-organization as well as efficacy characteristics. Khani et al. (2013) stated that spiritual leadership could also influence significantly on empowering employees. Ronizi and Ronizi (2013) described that some personal characteristics such as age, gender, educational background and job experience, only age could influence on empowering employees.

\section{The proposed study}

This paper studies the effects of different factors on empowering employees in one of Iranian food makers named Razavi Foods Products Co. The firm is one the leading companies with some experiences in advanced technology in the food industry. The firm started its activities in 1972 and in 1995, the firm successfully launched some fruit concentrate with 5 tons per hour production. They export their products to different continents such as Sweden, Holland, Kuwait, EAU, Iraq, Tajikistan, Turkmenistan, Pakistan Afghanistan, and some African countries.

The study considers the following six hypotheses,

1. There is a relationship between process optimization and empowering employees.

2. There is a relationship between appropriate work and empowering employees.

3. There is a relationship between knowledge, information as well as job skills and empowering employees.

4. There is a relationship between organizational relationships and empowering employees.

5. There is a relationship between timely promotion and empowering employees.

6. There is a relationship between objectives, responsibilities as well as authorities and empowering employees.

The study designs a questionnaire in Likert scale consists of 35 questions and distributes it among some employees of the firm. The sample size is calculated as follows,

$n=\frac{N \times z_{\alpha / 2}^{2} \times p \times q}{\varepsilon^{2} \times(N-1)+z_{\alpha / 2}^{2} \times p \times q}$,

where $N$ is the population size, $p=1-q$ represents the yes/no categories, $z_{\alpha / 2}$ is CDF of normal distribution and finally $\varepsilon$ is the error term. Since we have $p=0.5, z_{\alpha / 2}=1.96$ and $N=105$, the number of sample size is calculated as $n=83$.

In our survey, 65 employees were male and 18 employees were female. Fig. 1 shows other personal characteristics of the participants. 


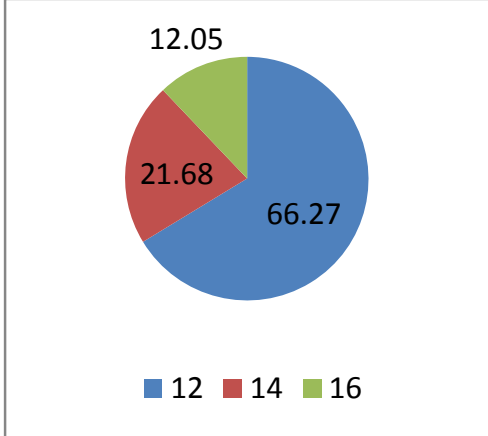

Years of education

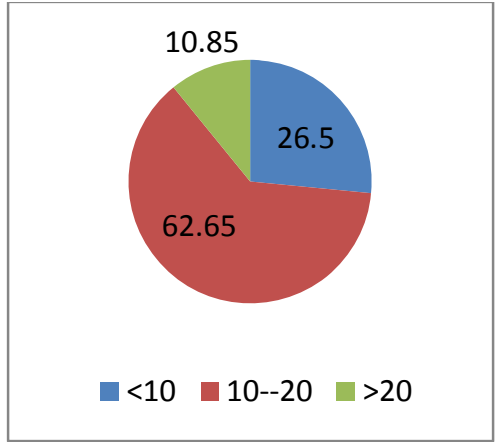

Job experience

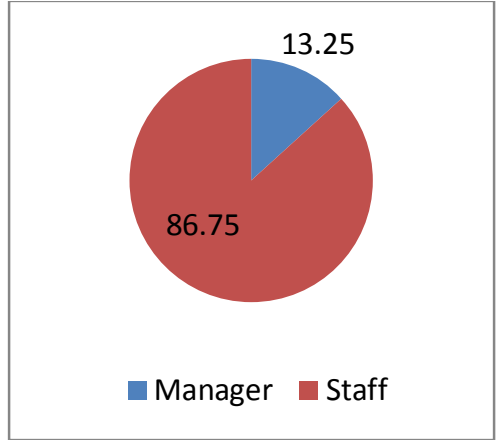

Position

Fig. 1. Personal characteristics of the participants

As we can observe from the results of Fig. 1, nearly two-third of the participants in our survey only finished high schools, $73 \%$ of them had at least 10 years of job experiences and most work as regular staff. The implementation of Kolmogorov-Smirnov test has indicated that all data were normally distributed and therefore, the study uses Pearson correlation test as well as stepwise regression technique to examine different hypotheses of the survey.

\section{The results}

In this section, we present details of the implementation of Pearson correlation test as well stepwise correlation test. Table 1 demonstrates the results of examining various factors on empowering employees.

\section{Table 1}

The summary of Pearson correlation test

\begin{tabular}{lccc}
\hline Variable & Correlation & Sig. & Result \\
\hline Group work & 0.554 & 0.000 & Confirmed \\
Communication & 0.789 & 0.000 & Confirmed \\
Work space & 0.955 & 0.000 & Confirmed \\
Process optimization & 0.879 & 0.000 & Confirmed \\
Information, skills & 0.829 & 0.000 & Confirmed \\
Objective, responsibilities and authorities & 0.895 & 0.000 & Confirmed \\
Job enrichment & 0.840 & 0.000 & Confirmed \\
Organizational dependability & 0.878 & 0.000 & Confirmed \\
Trust and friendship & 0.718 & 0.000 & Confirmed \\
Promotion and reward & 0.412 & 0.000 & Confirmed \\
\hline
\end{tabular}

As we can observe from the results of Table 1 all components of the survey influence positively empowering employees. Table 2 presents details of stepwise regression technique where empowering employees is dependent variable.

\section{Table 2}

The summary of stepwise regression technique

\begin{tabular}{lcccc}
\hline Variable & Coefficient & Standard error & F-value & Sig. \\
\hline Intercept & 0.9616 & 0.0648 & 219.79 & 0.000 \\
Work space & 0.335 & 0.0315 & 111.30 & 0.000 \\
Process optimization & 0.162 & 0.0235 & 47.51 & 0.000 \\
Information, skills & 0.128 & 0.0253 & 25.61 & 0.000 \\
Objective, responsibilities and authorities & 0.1547 & 0.0246 & 39.53 & 0.000 \\
\hline
\end{tabular}

According to the results of Table 2, four variables of work space, process optimization, information as well as skills and having crystal clear objectives, responsibilities and authorities influence on empowering employees. 


\section{Conclusion}

In this paper, we have presented an empirical investigation to study the effects of different factors on empowering employees in a food maker firm. The results of Pearson correlation test has indicated that work place was the most influential factor affecting positively on empowering employees followed by having crystal clear objectives on responsibilities and employees' authorities. In addition, the implementation of stepwise regression technique has indicated that work process was the most important factor followed by process optimization and having clear objectives.

\section{Acknowledgement}

The authors would like to thank the anonymous referees for constructive comments on earlier version of this paper.

\section{References}

Baird, J. (2006). The intent to leave: an investigation of empowerment mechanisms, job satisfaction, and organizational commitment among technical college employees (Doctoral Dissertation). Retrieved from ProQuest Dissertations and Theses database.

Darvish, H., Khani, A., Assarha, M \& Arani, H. (2013). A survey on the impact of the training period on empowering management team: A case study Saipa Group. Management Science Letters, 3(6), $1819-1824$

Kaye, B., \& Jordan-Evans, S. (2002). Love 'em or lose "em: Getting good people to stay (10thed.). San Francisco: Barrett-Koehler.

Khani, A., Darvish, H., Miandari, K \& Arani, H. (2013). The role of spiritual leadership on empowering employees: A case study of educational system. Management Science Letters, 3(3), 1013-1018.

Messmer, M. (2004). Creating an effective recognition program. Strategic Finance.

Petter, J., Byrns, P., Choi, D., Fegan, F., \& Miller, R. (2002). Dimensions and pallet in empowerment: Assessing what matters to street-level bureaucrats. Journal of Public Administration Research and Theory, 12, 377-396.

Ronizi, N \& Ronizi, Z. (2013). A study on different factors impacting creative habits. Management Science Letters, 3(1), 329-336.

Sadati, S. (2012). A survey relation of organizational culture and organizational citizenship behavior with employees' empowerment. Management Science Letters, 2(6), 2175-2186. 